\title{
Individual Differences in Strategy Use for L2 Lexical Inferencing: The Case of Learning Styles
}

\author{
Ming-yueh Shen (Corresponding author) \\ Department of Applied Foreign Languages, National Formosa University, 64, Wun-hua \\ Road, Huwei, Yun-lin, 632, Taiwan, ROC
}

Tel: 886-5-6315819Ｅ-mail: myshen@nfu.edu.tw

Received: July 11, 2017 Accepted: January 2, 2018 Published: January 5, 2018

doi:10.5296/elr.v4i1.12425 URL: http://doi.org/10.5296/elr.v4i1.12425

\begin{abstract}
This study aimed to examine the effect of the second language (L2) learners' perceptual learning style preferences on their strategy use for lexical inferencing and the treatment effect from an explicit instructional program. Joy Reid's (1995) Perceptual Learning Style Preferences (PLSP) Inventory, a lexical inferencing test, and a vocabulary strategy questionnaire were administered to 145 university students during a 15 -week reading course. The results of a simple regression analysis showed that the tactilc students tended to use more lexical inferencing strategies than the others with different learning styles; and that the visual learners tended to use strategies less frequently, compared to the other counterparts. Further analysis of simple regression indicated that the individual learners benefited most from the treatment effect, followed by the visual learners. The findings can be of significance for teachers and the L2 learners to concern individual differences in L2 inferential strategy use.
\end{abstract}

Keywords: Strategy use, Lexical inferencing, Perceptual learning style preferences

\section{Introduction}

Lexical inferencing from contextual clues is one of the most important strategies for successfully solving word problem in reading. Several previous studies (Nazmia, 2004; Nation, 2001; Oxford, 1990; Parel, 2004; Read, 2000; Wesche \& Paribakht, 2010) have indicated that lexical inferencing from information available in the text, i.e., using a variety of linguistic and nonlinguistic clues to guess word meaning, has been recognized in recent years as an important strategy for dealing with unknown words.

A number of previous studies have dealt with how inferencing strategies function and what factors are closely related to their success in meaning-inference (Bengelei \& Paribakht, 2004; Hu \& Nassaji, 2014; Nassaji, 2006; Paribakht \& Wesche, 2010). Hu and Nation (2000) investigated text related factors including word density and part of speech. Followed were 
other factors, such as types of reading tasks (i.e. cloze v.s. global reading), the strength and explicitness of clues, which were examined by Frantzen (2003). Syntactic complexity of texts (i.e., linguistic knowledge) was further explored (Kaivanpanah \& Alavi, 2008). Besides, a number of reader variables identified included the reader's reading profiles (e.g., knowledge of other languages, age of reading) (Levine \& Reves, 1998), learners' vocabulary knowledge (Dycus, 1997), and learners' memory capacity (Cain, Lemmon, \& Oakhill, 2004).

With regard to learners' factors, few studies have taken individual differences in learners, such as perceptual learning styles, into account when investigating learners' behaviors in strategy use for lexical inferencing. Underpinned by the notions that L2 teachers need to identify and understand their students' individual differences to provide more effective instruction (Ehrman, 1999) and that learning styles might be a predictor of foreign language acquisition (Ehrman, 1999), therefore, the present study aimed to explore how L2 learners' individual differences in perceptual learning style preferences affect their strategy use for lexical inferencing and treatment effect.

More specifically, the research questions were addressed as follows:

1) Do L2 learners' perceptual learning style preferences affect their strategy use for lexical inferencing?

2) Do L2 learners' perceptual learning style preferences affect the treatment effect?

\section{Literature Review}

\subsection{Lexical Inferencing Strategies}

Lexical inferencing strategies involve using a wide variety of linguistic or nonlinguistic clues to guess the word meaning (Oxford, 1990) when the learner encountered word problem. Lexical inferencing is further defined as an important strategy that involves a deeper processing of information available in the text itself and that is likely to contribute to better comprehension of the text as a whole (Read, 2000). Furthermore, Oxford (1990) suggested that proficient language learners are able to make educated guesses when encountered unknown words because successful readers use a wider range of strategies more frequently than their less successful counterparts.

However, Nassaji (2006) further suggested that success in lexical inferencing may depend not only on the use of certain strategies but also on the extent to which other sources of information inside and outside the text are combined and coordinated with. Nassaji (2006) indicated a significant link between learners' depth of vocabulary knowledge and the degree and type of the use of lexical inference strategy. He further claimed that those learners who possess a deeper lexical knowledge have better access to the knowledge sources to construct a more accurate semantic representation of the unknown words.

Other research examined how the learners used lexical inferencing strategies during L2 reading. Jelić (2007), for example, suggested that Croatian learners of French used semantic information most frequently at the sentence level, paragraph level and the text level. They also used their world knowledge about the topic of the text. However, they used, somewhat less frequently, word level information (i.e., parts of the word and its grammatical features), and analyzed grammatical features at the sentence level. That is, the students used global strategies more frequently than local strategies. 


\section{Macrothink}

The previous research also suggested that learners' language proficiency is closely related to strategy use. Shen (2009) indicated a significant correlation between Taiwanese EFL learners' reading proficiency and lexical inferencing strategy. In other words, the higher reading proficiency the learners, the more frequent use of strategies for lexical inferencing. Another study by İstifçi (2009) showed that the Turkish EFL learners at intermediate level were more successful than those at low-intermediate level in inferring the unknown words. In addition, while those at low-intermediate level got stuck on the unknown words when they read a passage, those at intermediate level used such strategies as discourse, world, grammatical, and word association knowledge to solve the word problem.

In recent years, research findings further suggest that what matters most in terms of lexical inferencing strategy use seems to be the way these strategies and knowledge sources are employed rather than the types and frequency of use. Oxford (2010) emphasized that good language learners are able to make a greater use of both cognitive and meta-cognitive strategies actively and constructively. $\mathrm{Hu}$ and Nassaji (2014) investigated the differences between successful and less successful inferencers in terms of the quantity and quality of strategy use. The findings confirmed that what distinguished successful from unsuccessful lexical inferencers depended not only on the degree to which they used certain strategies but also when and how to use them successfully. Like Oxford (2010), they indicated that successful inferences exhibited several important characteristics, such as frequent use of evaluation and monitoring strategies, a combination of both textual and background knowledge, self-awareness, and repeated efforts, to infer the target word meanings.

In summary, these research findings have examined the role of strategy use and lexical inferencing. However, successful strategy use for lexical inferencing still depends on a number of other factors, the role of which still needs to be considered and explored in an attempt to teach students how to use inferential strategies efficiently (Hu \& Nassaji, 2014). Insights into different aspects of lexical inferencing strategy use, such as underlying cognitive processes toward learners' individual differences, might be very valuable for teaching lexical inferencing.

\subsection{Perceptual Learning Style Preferences and Language Learning}

Learning style, one aspect of individual difference, is defined as a broader concept that includes cognitive as well as affective and physiological style. By examining four perceptual (auditory, visual, tactile learner, and kinesthetic) and two social (group and individual) learning style preferences, Reid (1995) designed the Perceptual Learning Style Preference (PLSP) questionnaire to identify ESL (English as a Second Language) /EFL (English as a Foreign Language) learners' perceptual-style-preferences.

According to Reid (1995), learners with different perceptual learning styles prefer different classroom activities. Visual learners tend to read and use mental image to learn a new language. They need the visual stimulation of bulletin boards, videos, and movies as well as written directions to function well in the classroom. Auditory learners enjoy the oral-aural learning channel and prefer to use memory strategies. Thus, they like to engage in discussions, conversations, and small group work. In contrast, tactile learners need to touch and handle objects and are happy with making artwork that is related to language learning. Therefore, they associate word information and meanings with involving hands-on learning such as 
writing and drawing. Kinesthetic learners also employ language authentically and require movement and frequent breaks in the classroom activity. They like TPR (Total Physical Response) activities, games, and role play that let them move around. Group learners tend to be more motivated when cooperative learning is emphasized (in Reid, 1995, pp. 35-36).

Additionally, individual learning style preferences play an important role in second and foreign language learning (Gardner, Tremblay, \& Masgoret, 1997). Several previous research has shown the relationship between learning styles and academic achievement and learners with different perceptual styles vary in their academic performance. Matthews (1996) indicated that learnes with certain styles perform more effectively than others for particular activities in the school environment. Kinsella (1995) found that ESL auditory learners often respond poorly to extensive written comments, questions, and corrections on a composition draft. Moreover, many academically-challenged adolescent and adult students in traditional classrooms learned more easily through tactual/kinesthetic and visual/nonverbal approaches than through auditory or visual/verbal approaches. As a result, Kinsella (1995) emphasized that the first step of teaching is to identify learners' learning style preferences. A further study by Collinson (2000) indicated that high-achieving participants preferred learning alone since they tended to be independent learners who required less environmental classroom structure, compared to their low-achieving counterparts.

Although these findings are not directly related to lexical inferencing, to help shed more light on L2 learners' lexical inferential behaviors, it is necessary to investigate if there is a relationship between types of learners' perceptual learning style preferences and the use of certain lexical inferencing strategies. It'd also worth exploring different responses, from the learners with different perceptual learning style preferences, to the instruction of lexical inferencing.

\section{Method}

\subsection{Participants}

This study involved 145 university students of different majors, e.g. English, Management of Information, and Mechanical Engineering. They were the learners of English and registered in an English course of a technical univerity in Taiwan. This study selected as more learners from different learning backgrounds as possible in order to enhance its reliability.

\subsection{Instruments}

\subsubsection{The Lexical Inferencing Test}

The target words were designed to meet the concern about text factors because the "percentage of known and unknown vocabulary" (Schmitt, 2000) was 96.7\%. The reading passages were low density texts (Laufer, 1997) with more nouns and verbs to facilitate guessing (Liu \& Nation, 1985). Those for the pretest and post test included 16 unknown words respectively ( 7 nouns, 7 verbs, 1 adjective, and 1 adverb in the pre-test; 7 nouns, 7 verbs, 2 adjectives in the post-test). In respect of the learner factors (i.e., limited ability and experience) (Frantzen, 2003; Levine \& Reves, 1998), two experienced high school teachers helped, by checking the vocabulary index in the textbooks for high school students, to verify if the target words were not taught before this study was conducted and if the texts matched the comprehension ability of the participants. 


\section{Macrothink}

The lexical inferencing test included eight short stories, with four for the pretest (Form A) and another four for the posttest (Form B). Each story contained approximately 110 to 125 words. Adopted from Multiple Reading Skills ( $2^{\text {nd }}$ edition) Book D (Boning, 1995), they met the same difficulty level--about $6^{\text {th }}$ to $7^{\text {th }}$ grade difficulty level according to Fry's Readability Graph. They were also paralleled with the genre for the pre-test and the post-tests: namely a description of an animal, the origin of a kind of fast food, a heart-warming story, and a description of an invention. A permission letter from McGraw-Hill Book Company to copy the texts was obtained in this study.

In the lexical inference test, the participants were first required to complete a target word list for word meaning in either Chinese or English without reading. Then, they read the texts and inferred the meanings of the target words with context from reading passages. They also needed to describe the clues and strategies they used to infer the word meaning. The treatment effect was measured by caculating the mean difference between the pretest and posttest.

\subsubsection{Vocabulary Strategy Questionnaire}

Cognition (e.g. guessing, analyzing, and reasoning) and metacognition (e.g., planning, monitoring, evaluation) usually interact with each other (O'Malley \& Chamot, 1995). Based on the interconnection of cognition and metacognition, the vocabulary strategy questionnaire, a 22-item Likert-type instrument adapted from Mineishi (1997), was designed and administered to investigate the students' perceptions of strategy use for the unknown words. Item analysis of each item indicated significance, at $p<.05$ and Cronbach's alpha reliability was .83. The questionnaire was sent to two evaluators with statistics background for peer review to determine its content validity. A native speaker of English helped proofread the content for meaning clarity.

Following Block's (1992) cognitive processing model of L2 lexical inference, which incorporates a generator and evaluator component and a metalinguistic control component, this study further categorized the 22 items into two parts: cognitive strategies (e.g. guessing, analyzing, and reasoning) and metacognitive strategies (e.g., planning, monitoring, evaluation). Part one includes a syntactic module, a semantic module, and a text schema module as the generator and evaluator component. To examine the learners' use of strategies to monitor and evaluate the guessing process, part two consists of several monitoring steps that the learners go through during the inferring process.

\subsubsection{Perceptual Learning Styles Preference Questionnaire (PLSPQ)}

Reid's PLSPQ (Perceptual Learning Styles Preference Questionnaire), reported to demonstrate high reliability (Peacock, 2001), was used to measure the EFL learners' perceputal learning style preferences. PLSPQ was chosen as a tool due to its ease of reading with a simple 30-question survey, and its free availability online for readers who may wish to use it in their classroom. Moreover, it is easy to administer and interpret. The 5-point Likert questionnaire with a 30 items assesses the preferred perceputal learning styles based on how the learners learn best by using their perceptions (visual, auditory, kinesthetic, and tactile) and social (group and individual) preferences. The participants indicated how they agreed with each item scaled from strongly agree to strongly disagree. The major learning style 
preference(s) is defined as a score between 38 and 50 indicates; 25-37 means minor learning style preference; 0-24 is negligible. In this study, a participating learner was categorized as a certain style of learner according to his/her major style when its highest mark was shown in the category.

\subsection{Data Collection Procedures}

First, a participant's score for the major learning style on the PLSPQ questionnaires was taken as his /her learning styles preference, as shown in Table 2. Then, the pre-lexical inferencing test lasted for ninety minutes to allow students enough time to read and describe how they infer the word meanings from the context clues. Also, students immediately responded to a vocabulary strategy questionnaire by indicating to what extent they used the strategy to deal with the target words. After a 15-week instruction, the post-lexical inferencing and the post-survey were administered to assess the treatment effect.

\subsection{Data Analysis}

The data from the five-point scale vocabulary strategy questionnaire were analyzed as five points for "strongly agree" and one point for "strongly disagree." A mean score of five indicated that the students perceived using the strategy with very high frequency, while a score of one meant that they perceived using the strategy none of the time.

To measure whether learners with different perceptual learning style preferences perform differently in strategy use for lexical inferencing, One-way ANOVA on the group means for different learning styles was carried out. To examine whether the L2 learners with diverse perceptual learning styles preference had different responses to the instruction of lexical inferencing strategies, Pearson Product Moment correlations and simple Regression analyses were also conducted for further analysis to calculate the coefficient for different strategy use between pre- and post-survey and analyze its relationship with individual learning style.

\subsection{The Instructional Program}

A 15-week explicit instructional program with lexical inferencing strategies was integrated into a formal reading course, as shown in Table 1. Designed with several practice sessions, the instructional framework was based on a combination of Winograd and Hare's (1988) explicit instruction model (i.e., consisting of six dimensions of good strategy instruction: what and why to learn, what the strategy is, how and when to use, and practice), and Clark and Nation's (1980) inductive procedure.

Table 1. Sample of the inferencing strategies and procedures

\begin{tabular}{lc}
\hline Strategies & Inductive Procedures \\
\hline *Lexical Knowledge: Using feature & Step 1: Decide on the part of speech of the \\
analysis to figure out word meaning based & unknown word. \\
on its similarity with other words (i.e. & \\
similar spelling) or word parts (i.e. verb, & \\
noun, or adjectives) & \\
*Monitoring: Elaborating the meaning by & Step 2: Look at the immediate context \\
talking to themselves, such as "Let me & surrounding the unknown word, \\
\hline
\end{tabular}


think," "well..." "Oh-oh" "Is this right?"

*Repeating: Repeating a word or a phrase either to show their difficulties in decoding the meaning or to allow themselves sufficient time for processing.

*Syntactic Knowledge : Using knowledge of grammatical function within or between sentences \& Monitoring

*Prior Knowledge: Associating a word together with another word based on background knowledge of the real world.\&* Self-inquiring: Asking oneself questions about the words already inferred

Self-inquiring, Monitoring \&

*Evaluating:

Evaluating and judged themselves on their accuracy when inferring the meaning of a word. simplifying it grammatically if necessary.

Examine the relationship between the unknown word and the known words surrounding it.

Step 3: Look at the wider context of the word; that is, the relationship with adjoining sentences or clauses. Examine the relationship between the unknown word and the known words before or after the sentences with the unknown word.

Step 4: Make connections between prior knowledge and text information.

Step 5: Guess.

Step 6: Check the guess by arousing metacognitive knowledge. For example, substitute the guess for the unknown word. Monitor the guess by asking yourself: "Does it fit comfortably into the context? Does it make sense?" Evaluate the guess to decide whether to accept the idea or reject it and then try again or seek outside assistance.

\section{Results}

4.1 Effect of Perceptual Learning Style Preferences on Strategy Use for L2 Lexical Inferencing

Table 2 presents the means for each group of learning style preferences, revealing that tactile learners tended to use more strategies for lexical inferencing, followed by group learners, auditory learners, kinesthetic learners, and individual learners. It was interesting to find that visual learners used lexical inferencing strategies less frequently than the other counterparts. 
Table 2. Mean and standard deviation of different learning style on strategy use (pre-test)

\begin{tabular}{llllll}
$\begin{array}{l}\text { Learning } \\
\text { Styles }\end{array}$ & Number & Mean & Std. Dev. & Minimum & Maximum \\
\hline Visual & 32 & 2.47 & 0.604 & 1.40 & 3.76 \\
Auditory & 33 & 2.69 & 0.619 & 1.56 & 3.68 \\
Kinesthetic & 26 & 2.58 & 0.556 & 1.32 & 3.96 \\
Tactile & 12 & 2.93 & 0.551 & 2.61 & 3.96 \\
Group & 21 & 2.75 & 0.652 & 1.68 & 3.76 \\
Individual & 21 & 2.49 & 0.532 & 1.44 & 3.40 \\
Total & 145 & 2.62 & 0.598 & 1.32 & 3.96 \\
\hline
\end{tabular}

However, a further analysis of one-way ANOVA, as shown in Table 3, suggested that the means among different learning styles were not significantly different, $F=1.540, p>.05$. That is, the EFL technical university learners in this study with different perceptual learning style preferences did not demonstrate significant difference in using lexical inferencing strategy for the unknown words. Prior to instruction, there was no significant difference among the learners of different perceptual learning style preferences in terms of using strategy to solve word problems.

Table 3. Results of ANOVA on strategy use for different learning styles

\begin{tabular}{llllll}
\hline Source & $d f$ & $S S$ & $M S$ & Fratio & Prob. \\
\hline Between-Gps & 5 & 1689.179 & 337.836 & 1.540 & .181 \\
Within-Gps & 139 & 30500.683 & 219.429 & & \\
Total & 144 & 32189.862 & & & \\
\hline
\end{tabular}

${ }^{*} p<.05$.

Additionally, regression analysis was calculated on the basis of the scores of individual learners. As shown in Table 4, only the mean score for tactile style learners differed significantly from that for individual learners $(p<.05)$, calculated as a constant for analysis. Statistically analyzed, only the score for the tactile learners was higher than the individual learners by 10.833. In other words, learners with tactile learning style tended to use more 
strategies for lexical inferencing than individual learners did. There was no significant difference among the others. However, it was also interesting to find that visual learners tended to use strategies less frequently, compared to the other counterparts.

Table 4. Coefficient of regression analysis on strategy use for different learning styles

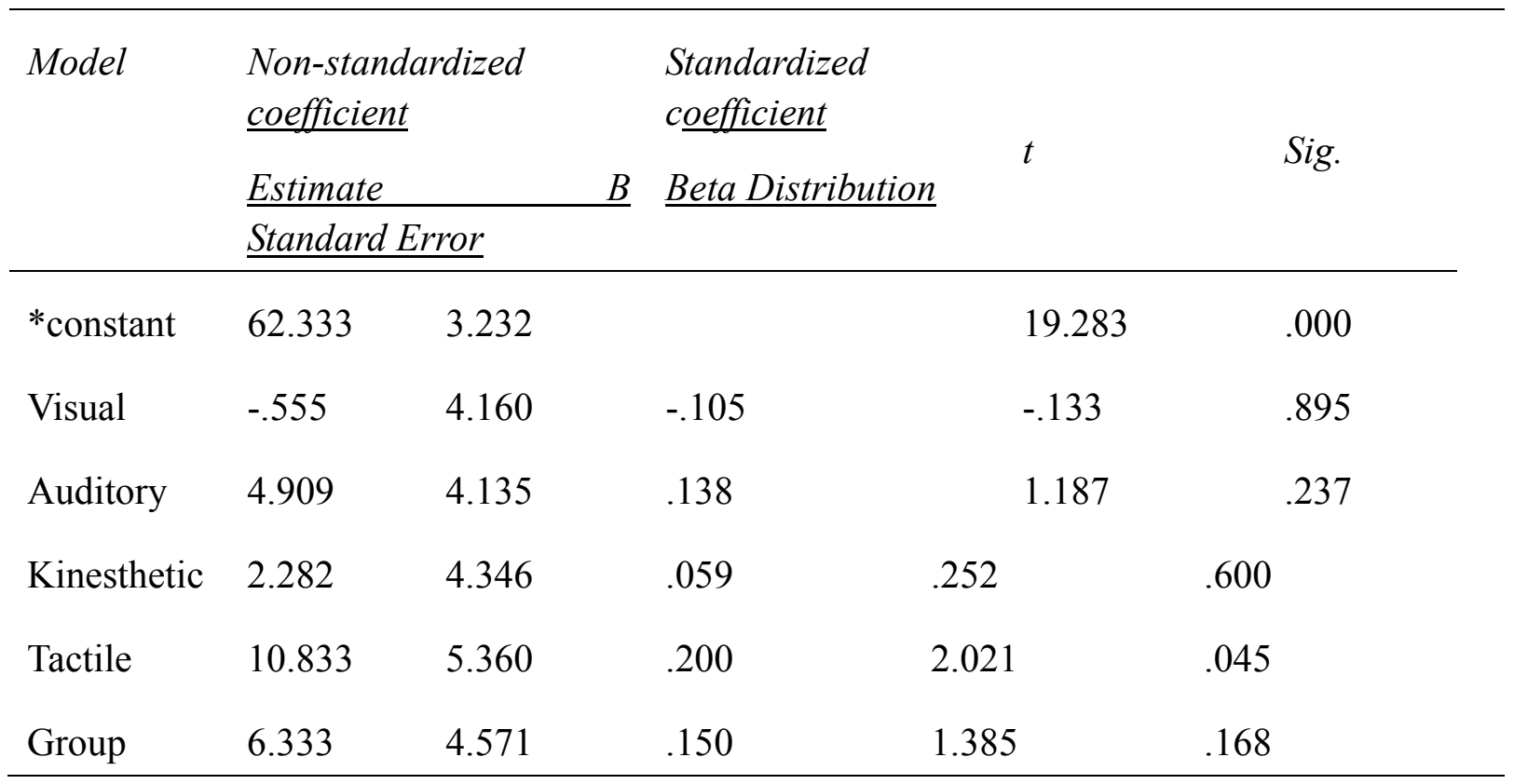

a. dependent variable: strategy use *constant: individual style.

4.2 Effect of Instruction on EFL Learners with Different Perceptual Learning Styles Preference in terms of Strategy Use

To measure whether learners with different learning styles benefited differently from instruction of lexical inferencing, a descriptive statistics and One-Way ANOVA on the group means of different learning styles were carried out. Table 5, 6, and 7 illustrate these results. Table 5 presents mean differences prior to and after lexical inferencing instruction with regard to strategy use. Results indicated that the individual learners benefited more from the instruction than other styles learners, while the tactile learners responded less than others to the lexical inferencing instruntion. 
Table 5. Gain means and standard deviation between pre-post- survey for strategy use

\begin{tabular}{llllll}
\hline $\begin{array}{l}\text { Learning } \\
\text { Styles }\end{array}$ & Number & Mean & Std. Dev. & Minimum & Maximum \\
\hline Visual & 32 & 18.9062 & 20.51020 & -25.00 & 82.00 \\
Auditory & 32 & 16.2812 & 15.68898 & -15.00 & 62.00 \\
Kinesthetic & 25 & 18.4400 & 15.89308 & -23.00 & 56.00 \\
Tactile & 12 & 10.0833 & 15.97986 & -8.00 & 38.00 \\
Group & 17 & 15.2353 & 12.67147 & -13.00 & 38.00 \\
Individual & 20 & 19.5500 & 15.59512 & -2.00 & 62.00 \\
Total & 143 & 17.0870 & 16.58267 & -25.00 & 82.00 \\
\hline
\end{tabular}

However, a further analysis of ANOVA revealed that there was no significant difference between learners with different perceptual learning styles preference in terms of the instruction effect on their strategy use. As shown in Table 6, the mean differences among different learning styles were not significantly different, $F=.676, p>.05$. That is, in this study, EFL technical university learners with different learning styles did not differ significantly from each other with respect to instruction effect on their strategy use.

Table 6. Results of ANOVA on treatment effect for different learning styles

\begin{tabular}{llllll}
\hline Source & $d f$ & $S S$ & $M S$ & F ratio & Prob. \\
\hline Between-Gps & 5 & 940.684 & 188.137 & .676 & .642 \\
Within-Gps & 132 & 36732.273 & 278.275 & & \\
Total & 137 & 37672.957 & & & \\
\hline
\end{tabular}

$* p<.05$.

Despite no significant differences, a simple regression analysis, on the basis of individual learning style as a constant variable, was conducted for another further analyses. Table 7 shows that all the other groups showed negative $t$ value, except individual learning group $(t=5.241)$. That is, the contextual instruction had more effect on individual learners than the others with regard to their strategy use for unknown words. Thus, it can conclude that the instruction effect on strategy use differed among learners with different styles, in which the 
individual learners benefited most, followed by visual learners, kinesthetic learners, auditory learners, group learners, and then tactile learners. Compared with other learning styles, tactile learners responded less to the instruction of lexical inferencing strategies.

Table 7. Coefficient of regression analysis on treatment effect for strategy use of different learning styles

\begin{tabular}{llllll}
\hline Model & \multicolumn{2}{l}{$\begin{array}{l}\text { Non-standardized coefficient } \\
\text { Estimate } \\
\text { Standard Error }\end{array}$} & $\begin{array}{l}\text { Standardized } \\
\text { coefficient } \\
\text { Beta } \\
\text { Distribution }\end{array}$ & $t$ & Sig. \\
\hline *onstant & 19.550 & 3.730 & & 5.241 & .000 \\
Visual & -.644 & 4.755 & -.016 & -.135 & .893 \\
Auditory & -3.269 & 4.755 & -.083 & -.687 & .493 \\
Kinesthetic & -1.110 & 5.004 & -.026 & -.222 & .825 \\
Tactile & -9.467 & 6.091 & -.161 & -1.554 & .123 \\
Group & -4.315 & 5.503 & -.086 & -.784 & .434 \\
\hline
\end{tabular}

a. dependent variable: strategy use *constant variable: individual style.

\section{Discussion}

This study examined how the EFL learners' perceptual learning style preferences affected their strategy use for lexical inferencing. Analyses of regression measures suggested that tactile learners used more strategies for lexical inferencing than individual learners, while visual learners tended to use strategies less frequently, compared to the other counterparts. However, no significant difference among the other learners was found. One possible explanation is that the tactile learners might tend to be intuitive learners who were found to rely heavily on guessing from context, and were comfortable with linguistic risks and experimentation, as shown in Ehrman and Oxford's study (1990). Moreover, they might also tend to be the perceiving learners, who were open to the ambiguities of the language learning process and flexible with using compensation strategies, such as guessing or improvising (Ehrman \& Oxford, 1990). A further study might be needed to investigate whether the tactile learners also tend to be more intuitive and perceiving.

The task factor might be another explanation to understand why the tactile learners used more strategy for lexical inferencing than visual or individual learners did prior to the instruction. According to Oxford (1990), guessing meanings is related to global learning because global learners enjoy getting the main idea and guessing meaning for the unknown words and 
concepts. This nature of inference and problem solving might be more suitable to mixed modality or group/tactile learners, while strong visual or auditory learners do better with the task done in a systematic way (Reid, 1995). In this study, it seemed that the visual learners did not show natural inference and risk-taking tendencies in a lexical inferencing test prior to the instruction.

In addition, the results indicated that treatment effects on strategy use for lexical inferencing varied among learners with different perceptual learning style preferencess, in which the individual learners benefited most, followed by visual learners. This finding, partially consistent with Shen (2010), showing certain style preferencers, particularly the individual or visual learners, expressed more positive response to the training program. In line with the notion of matching teaching and learning style, we speculated that in an Asian EFL classroom, explicit and direct instruction is usually implemented in favor of the individual / visual learners. Those with such learning styles preferences might tend to be sensing, thinking, and judging types, which were indicated by Ehrman and Oxford (1990) to be more structured-oriented and advantaged in a classroom with unambiguous, sequenced, orderly, and predictable goals. A further study is also needed to examine whether individual or visual learners reveal higher tolerance to unambiguous learning context and reponded positively to the explicit instruction.

On the other hand, these findings (as shown in Table 1) suggest that tactile or group learners might be intuitive and perceiving and showed antipathy towards a pre-structured and systematic syllabus (Ehraman \& Oxford, 1990), resulting in less success after the explicit instruction on lexical inferencing strategies. It seems that group and tactile learners did not rely on the instruction because they did not need to develop additional conscious strategies or because their strategy use might have been automatic (Shen, 2010). In other words, they could be able to take what they already have to solve word problems and too many routines and practices in the explicit instruction might decrease their serendipitous learning.

In summary, this study demonstrated that the EFL learners' perceptual learning style preferences played a role in their strategy use for lexical inferncing. However, the homogeneity of the participants in their educational and culture background might be one of the reasons that resulted in less clear-cut differences in strategy use between learners with different learning style preferences. Although it should be cautious to generalize this conclusion, these findings support Matthews (1996) and Oxford (1990) that learners with different perceptual styles responded differently to different classroom tasks. This study suggests the importance of matching the learners' learning styles with an educational setting.

\section{Conclusion and Pedagogical Implications}

This study examined how the EFL university learners' perceptual learning style preferences affected their strategy use for lexical inferencing. While perceptual learning style preferences was evidenced as a factor for L2 lexical inferencing, these findings sugggest that other complicated affective factors such as motivation and measurement method should be taken into consideration.

Despite its limits, this study suggests several implications for classroom practices. Firstly, the EFL teachers should pay attention to the learners' learning style preferences when desiging 
the course for lexical inferncing. They should provide various teaching methods and materials to balance the learning opportunities for students with diverse learning styles. Secondly, the EFL teachers should emphasize the effective inferencing strategies to enhance the learning process. Teachers should be sensitive to the different needs revealed from the different learnes with different learning style preferences and then adjust the couse design to meet the learners' individual needs as detailed as possible.

Although these findings suggest the awareness of learners' individual differences in L2 lexical inferncing, it needs an in-depth qualitative analysis and a more open-ended ethnographic technique for data collection. For the future research, other individual difference factors, such as learning motivation, learning anxiety, as well as teaching styles should alos be included.

\section{Acknowledgements}

This project was funded by National Formosa University (TCS-096053). I'd would like to thank Chi-Hung Wu for his assistance in data analysis and Mr. Robert Howkins for his proofreading my manuscript. Thanks also go to the students who participated in this study.

\section{References}

Bengeleil, N. F., \& Paribarkht, T. S. (2004). L2 proficiency and lexical inferencing by university EFL learners. The Canadian Modern Language Review, 61(2), 225-249. https://doi.org/10.3138/cmlr.61.2.225

Block, E. L. (1992). See how they read: Comprehension monitoring of L1 and L2 readers. TESOL Quarterly, 26(2), 319-338. https://doi.org/10.2307/3587008

Boning, R. A. (1995). Multiple Reading Skills, Book D ( $2^{\text {nd }}$ Ed.). Singapore: McGraw-Hill, Inc.

Cain, L., Lemmon, K., \& Oakhill, J. (2004). Individual differences in the inference of word meanings from context: the influence of reading comprehension, vocabulary knowledge, and memory capacity. Journal of Educational Psychology, 96(4), 671-68. https://doi.org/10.1037/0022-0663.96.4.671

Carrell, P. L., \& Prince, M. S. (1996). Personality types and language learning in an EFL context. Language Learning, 46(1), https://doi.org/10.1111/j.1467-1770.1996.tb00641.x

Clark, D. F., \& Nation, S. P. (1980). Guessing the meanings of words from context: strategy and techniques. System, 8, 211-220. https://doi.org/10.1016/0346-251X(80)90003-2

Collinson, E. (2000). A survey of elementary students' learning style preferences and academic success. Contemporary Education, 71(4), 42-48.

Dycus, D. (1997). Guessing word meaning from context: should we encourage it? Literacy Across Cultures, 1(2), 1-6.

Ehrman, M. (1999). Ego boundaries and tolerance of ambiguity in second language learning. In J. Arnold (Ed.), Affect in Language Learning (pp. 68-86). New York : Cambridge UP.

Ehrman, M., \& Oxford, R. (1990). Adult language learning styles and strategies in an intensive training setting. Modern Language Journal, 74, 311-326. https://doi.org/10.1111/j.1540-4781.1990.tb01069.x 
Felder, R. M., \& Henriques, E. R. (1995). Learning and teaching styles in foreign and second language education. Foreign Language Annals, 28, 21-31. https://doi.org/10.1111/j.1944-9720.1995.tb00767.x

Frantzen, D. (2003). Factors affecting how second language Spanish students deriving meaning from context. The Modern Language Journal, 87, 168-199. https://doi.org/10.1111/1540-4781.00185

Fukkink, R. G., Block, H., \& Glopper, K. D. (2001). Deriving word meaning from written context: a multicompontential skill. Language Learning, 51(3), 477-496. https://doi.org/10.1111/0023-8333.00162

Gardner, R. C., Tremblay, P. E., \& Masgoret, A-M. (1997). Towards a full model of second language learning: an empirical investigation. The Modern Language Journal, 81(3), 344-362. https://doi.org/10.1111/j.1540-4781.1997.tb05495.x

Hu, H. C., \& Nassaji, H. (2014). Lexical inferencing strategies: The case of successful versus less successful inferencers. System, 45, 27-38. https://doi.org/10.1016/j.system.2014.04.004 İstifçi, İ. (2009). Lexical inferencing strategies of Turkish EFL learners. Journal of Language and Linguistic Studies, 5(1), 97-109.

Jelić, A.-B. (2007). Lexical inferencing strategy use by Croatian foreign-language learners. In J. Horváth, \& M. Nikolov (Eds.), UPRT 2007: Empirical studies in English applied linguistics (pp. 245-254). Pécs: Lingua Franca Csoport.

Kaivanpanah, S., \& Alavi, S. M. (2008). The role of linguistic knowledge in word-meaning inferencing. System, 36, 172-195. https://doi.org/10.1016/j.system.2007.10.006

Kinsella, K. (1995). Understanding and empowering diverse learners in ESL classroom. In M. J. Reid (Ed.), Learning styles in the ESL/EFL classroom (pp. 74-86). Boston, MA: Heinle \& Heinle Publishers.

Kroonenberg, N. (1995). Meeting language learners' sensory-learning-style preferences. In Joe. M. Reid (Ed.), Learning styles in the ESL/EFL classroom (pp. 74-86.). Boston: Heinle \& Heinle Publishers.

Laufer, B. (1997). The lexical plight in second language reading. In J. Coady, \& T. Huckin (Eds.), Second Language Vocabulary Acquisition (pp. 20-34). UK: Cambridge University Press.

Levine, A., \& Reves, T. (1998). Interplay between reading tasks, reader variables and unknown word processing. TESL-EJ, 3(2), 1-12.

Liu N., \& Nation, I. S. P. (1985). Factors affecting guessing vocabulary in context. RELC Journal, 16(1), 33-42. https://doi.org/10.1177/003368828501600103

Matthews, D. (1996). An investigation of learning styles and perceived academic achievement for high school students. The Clearing House, 69, 249-254.

Mineishi, M. (1997). A study about the relationship between reading ability of Japanese EFL university students and vocabulary strategies. Bulletin of English Education Society in Chugoku area, 27, 177-188.

Nassaji, H. (2006). The relationship between depth of vocabulary knowledge and L2 learners' lexical inferencing strategy use and success. The Modern Language Journal, 90(3), 
387-401. https://doi.org/10.1111/j.1540-4781.2006.00431.x

Nation, P. (2001). Learning vocabulary in another language. Cambridge, UK: Cambridge University Press. https://doi.org/10.1017/CBO9781139524759

Nazmia, B. F. (2004). L2 reading proficiency and lexical inferencing by university EFL learners. The Canadian Modern Language Review, 61(2), 225-249. https://doi.org/10.3138/cmlr.61.2.225

O'Malley, J. M., \& Chamot, A. U. (1995). Learning Strategies in Second Language Acquisition. Cambridge, NY: Cambridge University Press.

Oxford, R. L. (1990). Language Learning Strategies: What Every Teacher Should Know. NY: Newbury House.

Parel, R. (2004). The impact of lexical inferencing strategies on second language reading proficiency. Reading \& Writing, 17(6), 847-873. https://doi.org/10.1007/s11145-004-9347-6

Peacock, M. (2001). Match or mismatch? Learning styles and teaching styles in EFL. International Journal of Applied Linguistics, 11(1), 38-58. https://doi.org/10.1111/1473-4192.00001

Read, J. (2000). Assessing vocabulary. UK: Cambridge University Press. https://doi.org/10.1017/CBO9780511732942

Reid, J. M. Ed. (1995). Learning Styles in the ESL/EFL Classroom. Boston: Heinle \& Heinle Publishers.

Schmitt, N. (2000). Vocabulary in Language Teaching. UK: Cambridge University Press.

Shen, M-Y. (2009). Technical university EFL learners' reading proficiency and their lexical inference performance. Electronic Journal of Foreign Language Teaching (e-FLT)-Center for Language Study /National University of Singapore, 6(2), 189-200.

Shen, M-Y. (2010). Effects of perceptual learning style preferences on L2 lexical inferencing. System, 38, 539-547. https://doi.org/10.1016/j.system.2010.09.016

Wesche, M., \& Paribakht, S. (2010). Reading-based exercised in second language vocabulary learning: an introspective study. The Modern Language Journal, 84, 196-213. https://doi.org/10.1111/0026-7902.00062

Winograd, P., \& Hare, V. C. (1988). Direct instruction of reading comprehension strategies: The nature of teacher explanation. In C. E. Weinstein, E. T. Goetz, \& P. A. Alexander (Eds.), Learning and study strategies: Issues in assessment, instruction, and evaluation (pp. 121-139). San Diego, CA: Academic Press. https://doi.org/10.1016/B978-0-12-742460-6.50014-1

\section{Copyright Disclaimer}

Copyright reserved by the author(s).

This article is an open-access article distributed under the terms and conditions of the Creative Commons Attribution license (http://creativecommons.org/licenses/by/3.0/). 
